\title{
Acetaldehyde as a drug of abuse: insight into AM281 administration on operant-conflict paradigm in rats
}

\author{
Fulvio Plescia, Anna Brancato, Rosa A. M. Marino and Carla Cannizzaro* \\ Laboratory of Neuropsychopharmacology, Section of Pharmacology, Department of Sciences for Health Promotion and Mother and Child Care "Giuseppe \\ D'Alessandro," University of Palermo, Palermo, Italy
}

Edited by:

Merce Correa, Universidad Jaume, Spain

Reviewed by:

John D. Salamone, University of

Connecticut, USA

Marco Diana, University of Sassari,

Italy

\section{*Correspondence:}

Carla Cannizzaro, Laboratory of Neuropsychopharmacology,

Department of Sciences for Health Promotion and Mother and Child Care "Giuseppe D'Alessandro," University of Palermo, Via del Vespro 129, 90127 Palermo, Italy e-mail: carla.cannizzaro@unipa.it; carla.cannizzaro@katamail.com
Increasing evidence focuses on acetaldehyde (ACD) as the mediator of the rewarding and motivational properties of ethanol. Indeed, ACD stimulates dopamine release in the nucleus accumbens and it is self-administered under different conditions. Besides the dopaminergic transmission, the endocannabinoid system has been reported to play an important role in ethanol central effects, modulating primary alcohol rewarding effect, drug-seeking, and relapse behavior. Drug motivational properties are highlighted in operant paradigms which include response-contingent punishment, a behavioral equivalent of compulsive drug use despite adverse consequences. The aim of this study was thus to characterize ACD motivational and rewarding properties employing an operant-conflict paradigm in which rats, trained to lever press in order to get ACD solution $(0.9 \%)$, undergo extinction, reinstatement and conflict sessions, according to a modified Geller-Seifter procedure. Furthermore, the role played by CB1 receptor system in modulating ACD-induced effects were investigated through the administration of CB1 receptor antagonist, AM281 (1 mg/kg, i.p.) during the extinction-, relapse-, and conflict-experiments. Our results indicate that ACD is able to induce and maintain an operant behavior, a high number of responses during extinction, an increase in the lever presses during the reinstatement phase, and a higher emission of punished responses during the conflict experiments, when compared to controls. The administration of AM281 is able to decrease ACD-seeking behavior during extinction, the number of lever presses during reinstatement and to strongly decrease the punished responses for ACD. Our data strengthen the idea that ACD may be responsible for the central effects of ethanol, and pinpoint at the CB1 system as one of the neural substrates underlying its addictive properties.

Keywords: acetaldehyde, lever pressing, relapse, Geiller-Seifter procedure, CB1 receptor blockade/antagonism

\section{INTRODUCTION}

Evidence obtained in preclinical studies suggests that Acetaldehyde (ACD), the first metabolite of ethanol, is biologically active and may play a pivotal role in the rewarding, motivational and addictive properties of alcohol, as recently reviewed by Correa et al. (2012) and Deehan et al. (2013a).

ACD is obtained from ethanol oxidative metabolism, which occurs by peripheral alcohol dehydrogenase, and by central catalase and CYP2E1 (Zimatkin et al., 1998; Arizzi-LaFrance et al., 2006; Zakhari, 2006; Jamal et al., 2007). High blood levels of ACD enter the brain, likely overwhelming the aldehyde dehydrogenase present in the blood-brain barrier (Quertemont et al., 2005).

ACD is able to affect dopamine neurotransmission, increasing neuronal firing in the ventral tegmental area (VTA), thus stimulating DA release in the nucleus accumbens (NAcc) shell (Melis et al., 2007; Deehan et al., 2013b). Recent reports show that the intra-VTA administration of a lentiviral vector, able to inhibit catalase synthesis, and hence central ACD production, nearly abolishes voluntary ethanol intake, as well as decreases ethanolinduced DA release in the NAcc shell (Karahanian et al., 2011), further supporting the compelling theory that ethanol may be acting as a prodrug. Behavioral studies confirm that ACD administration is able to induce conditioned place preference (Smith et al., 1984; Peana et al., 2008); furthermore rats readily selfadminister ACD solution in operant conditions through several routes: centrally (Amit et al., 1977; Brown et al., 1979; Rodd et al., 2005), and peripherally (Myers et al., 1982; Peana et al., 2010; Cacace et al., 2012).

Besides the dopaminergic transmission, the brain endocannabinoid (EC) system plays an important role in valueattribution processing and in the modulation of reward-seeking behavior for different drugs of abuse (Serrano and Parsons, 2011), in view of its role as fine modulator of incoming inputs within the VTA (Melis et al., 2012).

In particular, $\mathrm{CB} 1$ receptor manipulation is reported to affect ethanol-related behavior, and in fact CB1 antagonism decreases both voluntary ethanol intake and relapse to ethanol in several experimental models (Arnone et al., 1997; Colombo et al., 1998; Gallate and McGregor, 1999; Cippitelli et al., 2005; Economidou et al., 2006; Femenía et al., 2010; De Bruin et al., 2011; Getachew et al., 2011), suggesting that CB1 receptor blockade reduces the rewarding value of ethanol. In turn, chronic administration of 
ethanol is associated with increased concentrations of endocannabinoids, in accordance with a reduction in the activity of their removal mechanisms, and in CB1 receptor expression, thus affecting the system as a whole (Basavarajappa et al., 1998, 2000, 2003; Vinod et al., 2006).

Given these premises, it is worth focusing on $\mathrm{CB} 1$ receptor involvement in ACD self-administration, employing an operant conditioning paradigm which may reliably model the distinct phases of the addiction cycle. Indeed, punishment resistance, which represents the behavioral equivalent of compulsive drug use despite negative consequences (Deroche-Gamonet et al., 2004), is considered as a mandatory component in mirroring the addictive phenotype, besides drug taking, drug seeking and relapse (Marchant et al., 2013). Hence, by the assessment of the capacity of orally self-administered ACD to induced and maintain an operant behavior after forced abstinence, and in the presence of an aversive stimulus, according to a programmed schedule of responding (Cannizzaro et al., 2011; Cacace et al., 2012), the evaluation of the influence of CB1 receptor blockade by AM281 was carried out on ACD-seeking and relapse, and on compulsive-like behavior.

\section{MATERIALS AND METHODS ANIMALS}

Adult male Wistar rats (Harlan, Udine, Italy) weighing 250 to $300 \mathrm{~g}$, were housed two per cage and maintained on a 12-h light/dark cycle, under controlled environmental conditions (temperature $22 \pm 2{ }^{\circ} \mathrm{C}$; humidity $55 \pm 10 \%$ ) with food and water available ad-libitum. During operant behavior experiments they were water-restricted and allowed to drink only $1 \mathrm{~h} /$ day at the end of the experimental sessions. Water intake was recorded. All subjects were experimentally naive and randomly assigned to the following groups $(n=16)$ : ACD-drinking rats (ACD) which selfadministered a solution of ACD $(0.9 \% \mathrm{v} / \mathrm{v})$ and water-drinking rats (CTR) which self-administered water. All experiments were in accordance with the Committee for Use of Experimental Animals of the University of Palermo, the Italian legislation D.L. 116/1992 and the European Union Council Directive 2010/63, dealing with research on experimental animals.

\section{DRUGS}

ACD 99.98\% (Sigma-Aldrich, Milan, Italy) was diluted in tap water, in order to achieve a final concentration of $0.9 \% \mathrm{v} / \mathrm{v}$ $(0.450 \mathrm{ml}$ ACD in $50 \mathrm{ml}$ of water $)$. ACD solution was daily prepared, sealed with Parafilm (American Can Company), stored at $4^{\circ} \mathrm{C}$ during experiments, aiming at avoiding concentration loss (Cacace et al., 2012).

The CB1 selective cannabinoid antagonist AM281 (SigmaAldrich, Milan, Italy) was dissolved in a vehicle of Tween 80 $(3 \%)$ in saline solution $(0.9 \% \mathrm{NaCl})$, and administered intraperitoneally $(1 \mathrm{mg} / \mathrm{kg})$.

\section{APPARATUS}

The experimental sessions were carried out in a custom-built operant-conditioning chamber $(30 \times 28 \times 37 \mathrm{~cm})$, included in a dim-illuminated, ventilated, sound-attenuating cubicle. The chamber was equipped with one active lever and a cup that collected liquid from a corked reservoir, aiming at ACD solution preservation from evaporation, with a solenoid-actuated delivery system. It assured the delivery of $0.05 \mathrm{ml}$ of solution for each lever pressing. Moreover, a foot-shock generator was able to deliver a constant-current, intermittent, inescapable, foot-shock $(0.2 \mathrm{~mA})$ to the chamber grid floor. A light-cue above the lever turned on during the punished period, allowing the animals to be aware of the aversive stimulus. Animal performance was recorded on a counter connected to the chamber. The devices were thoroughly cleaned before the introduction of each animal to ensure that the particular rat's behavior was not affected by the detection of another rat's scent.

\section{OPERANT SELF-ADMINISTRATION PROCEDURE}

The lever pressing procedure was scheduled into four different periods: Training-rewarded responses under a continuous schedule of reinforcement; Extinction-non rewarded responses; Relapse-reinstatement of the reinforced operant behavior following 1 week-deprivation; Conflict-rewarded responses cyclically associated with a $0.2 \mathrm{~mA}$ footshock.

\section{Shaping and training}

Animals underwent water deprivation for $23 \mathrm{~h}$ and then they were shaped to lever press in order to obtain water on a continuous reinforcement schedule (fixed ratio 1), until they achieved a steady performance. Afterwards, during the Training session rats orally self-administered ACD solution or water, according to their group, in the operant chamber, under a fixed ratio 1, along 21 days. For each operant response, the system delivered $0.05 \mathrm{ml}$ of water or $0.90 \% \mathrm{v} / \mathrm{v}$ ACD solution. The number of lever presses was automatically recorded. Animals were tested each day at the same time (9:00 to 14:00), and each trial lasted $20 \mathrm{~min}$.

\section{Extinction}

Animals underwent an operant responding session during which reward delivery was suspended. The number of lever presses at the end of the 20 min session was recorded for both ACD and Control groups.

\section{Deprivation}

ACD self-administration was suspended for 7 days to achieve a forced abstinence. Rats were left undisturbed in their home cages and received water and food ad-libitum.

\section{Relapse}

After the deprivation period, rats were exposed again to lever pressing in the operant chamber with a fixed ratio 1 response schedule for 7 days. Responses for ACD or water were recorded during the 20 min-experimental sessions.

\section{Conflict}

This protocol represented a modification of the Geller-Seifter paradigm, a procedure in which a positive reinforcement (water or ACD solution) is earned by an operant response; however, delivery of the positive reinforce is paired with an aversive stimulus, as a footshock. In our study, animals underwent alternatively unpunished and punished responses according to " 3 minutes1 minute" schedule. The session started and ended with an 
unpunished interval. The punishment was signaled by a cue-light triggered by the response. During the punished response interval, lever presses were rewarded with the solution and coupled with a mild footshock of $0.2 \mathrm{~mA}$. The number of unpunished and punished responses was automatically recorded.

\section{Treatment}

CB1 antagonist AM281 was administered to ACD-group $30 \mathrm{~min}$ before the experimental sessions, during extinction (1 day), relapse ( 7 days), and conflict (7 days). Control rats were administered intraperitoneally with vehicle.

\section{Statistical analysis}

Operant-drinking behavior. A Two-Way analysis of variance (ANOVA) was conducted on the number of lever presses during the training, extinction-, relapse- and conflict-sessions, as dependent variables, with "ACD self-administration" (treatment) as between-subjects factor, and "days" as repeated measurement factor. When necessary, simple main effects and post-hoc comparisons were calculated with Bonferroni post-test $(\alpha=0.05)$. Differences were considered statistically significant if $p<0.05$. Furthermore, to compare the effect of AM281 treatment on ACDseeking behavior during extinction, a 2-tailed Student's $t$-test for unpaired measures was employed.

\section{RESULTS}

\section{OPERANT SELF-ADMINISTRATION}

\section{Training period}

The results of a Two-Way ANOVA for repeated measures including ACD treatment as the between-subjects factor and "Days" as within-subjects factor showed a significant effect of time, treatment, and their interaction on the number of responses emitted, $F_{(20,600)}=19.52, p<0.0001 ; F_{(1,30)}=5.16, p<0.0304$; $F_{(20,600)}=26.81, p<0.0001$. Although during the training period both groups showed a similar pattern of operant-drinking behavior, post-hoc analysis revealed significant differences along the paradigm (Figure 1). In particular, at the beginning, rats exposed for the first time to ACD in the operant paradigm, showed a lower number of lever presses, and consequently a reduced liquid intake, reaching an amount of ACD consumed of $259 \pm 68 \mathrm{mg} / \mathrm{kg}$ In the second week of the paradigm, ACD rats' drinking behavior increased, displaying higher number of lever presses and greater liquid intake 3 days of 7 , displaying an average intake of $325 \pm 21 \mathrm{mg} / \mathrm{kg}$. Values from the third week of training were considered as reference measure of ACD baseline operant behavior. In this week, ACD rats' lever presses were increased significantly with respect to controls, 6 days of 7 ( $t=7.32, p<$ $0.001 ; t=3.106, p<0.05 ; t=6.359, p<0.001 ; t=6.906, p<$ $0.001 ; t=5.843, p<0.001 ; t=5.745, p<0.001)$, for a mean ACD intake of $355 \pm 17 \mathrm{mg} / \mathrm{kg}$. When water intake was measured during the free-drinking hour at the end of the experimental sessions, no differences were observed between the two experimental groups.

\section{Extinction}

Rats were tested on the operant condition paradigm to assess drug seeking when reward delivery was suspended. The effects of AM281 treatment on ACD seeking behavior in terms of lever presses were analyzed by a two-tailed Student' $t$-test for unpaired measures. Our data indicated that ACD was able to induce a significant increase in the number of lever presses $(t=5.152, d f=$ $30, p<0.001)$ compared to control rats. AM281 administration induced a reduction in the number of lever presses $(t=4.196$, $d f=30, p<0.001$ ) in ACD group (Figures 2A,B). AM281 was ineffective on control rats' operant behavior for water.

\section{Relapse}

Following 7 days of abstinence from ACD self-administration, rats were tested again in the operant chamber to assess whether deprivation could influence their drinking behavior. The results of a Two-Way ANOVA for repeated measures including ACD treatment as the between-subjects factor and "Days" as withinsubjects factor showed a significant effect of time, treatment, and

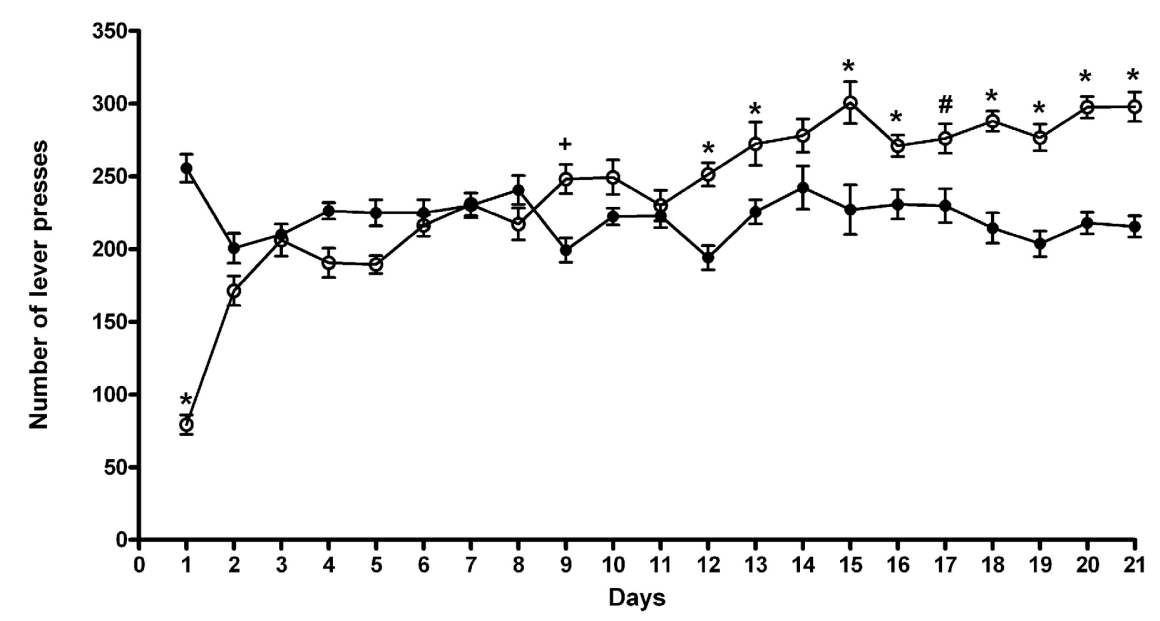

FIGURE 1 | Number of lever presses during the 21 days of training period. Each value represents the means \pm S.D. of 16 rats. ${ }^{\#} p<0.05 ;{ }^{+} p<0.01 ;$ ${ }^{*} p<0.001$ vs. control groups. (๑) CTR, (O) ACD. 
their interaction on the number of responses emitted, $F_{(6,180)}=$ $14.21, p<0.0001 ; F_{(1,180)}=41.14, p<0.001 ; F_{(6,180)}=15.79$, $p<0.0001$. Bonferroni post-hoc analysis showed that ACD group displayed an increased number of lever presses on day 1, 2, 4, 6 , and 7 ( $t=8.008$., $p<0.001 ; t=4.173, p<0.001 ; t=6.574$, $p<0.001 ; t=8.231, p<0.001 ; t=4.320, p<0.001)$ when compared to controls (Figure 3A), reaching an average intake of $409 \pm 37 \mathrm{mg} / \mathrm{kg}$. Furthermore, when animals received the selective cannabinoid antagonist AM281, statistical analysis performed by a Two-Way ANOVA for repeated measures, including AM281 treatment as the between-subjects factor and "Days" as withinsubjects factor, showed a significant effect of time, treatment, and their interaction on the number of responses emitted, $F_{(6,180)}=$ $4.61 p<0.0002 ; F_{(1,180)}=39.57, p<0.001 ; F_{(6,180)}=7.82$, $p<0.0001$. Bonferroni post-hoc analysis showed that AM281 was able to induce a reduction in the number of lever presses in all days of relapse $(t=4.763, p<0.001 ; t=6.836, p<$ $0.001 ; t=3.028, p<0.05 ; t=4.522, p<0.001 ; t=3.944, p<$ $0.001 ; t=7.936, p<0.001 ; t=5.448, p<0.001)$ in ACD group

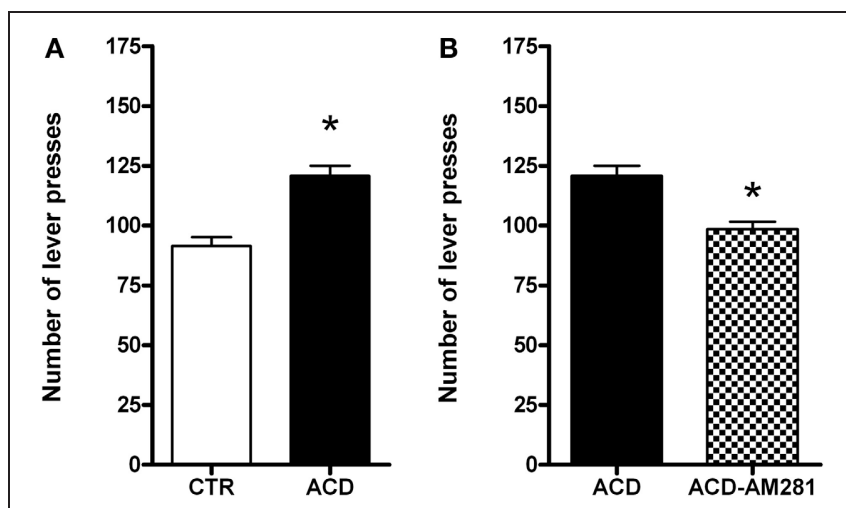

FIGURE 2 | Effects of ACD (A) and AM281 treatment (B) on the number of lever presses during the extinction day. Each value represents the means \pm S.D. of 16 rats. ${ }^{*} p<0.001$ vs. respective control groups.
(Figure 3B) leading to a decrease in the amount of ACD consumed $(266 \pm 16 \mathrm{mg} / \mathrm{kg})$. No significant differences in the number of lever presses were recorded when AM281 was administered to control rats.

\section{Conflict}

In this set of experiments, rats underwent a cyclic schedule of unpunished and punished rewarded responses. Results of a TwoWay ANOVA for repeated measures, including ACD treatment as the between-subjects factor and "Days" as within-subjects factor on unpunished responses, showed a significant effect of time, treatment, and their interaction on the number of responses emitted, $F_{(6,180)}=3.80, p<0.0014 ; F_{(1,180)}=74.32, p<0.0001$; $F_{(6,180)}=2.35, p<0.0328$. Bonferroni post-hoc analysis showed that ACD group displayed an increase in the number of unpunished lever presses on day $1,2,3,4,5$, and $6(t=5.009, p<0.001$; $t=5.417, p<0.001 ; t=3.064, p<0.05 ; t=4.686, p<0.001$; $t=3.677, p<0.01 ; t=5.817, p<0.001)$ when compared to controls (Figure 4A), and greater amount of ACD consumed $(377 \pm 31 \mathrm{mg} / \mathrm{kg})$. When the parameter "punished responses" was analyzed, a Two-Way ANOVA for repeated measures including ACD treatment as the between-subjects factor and "Days" as within-subjects factor, showed a significant effect of time, treatment, and their interaction on the number of responses emitted, $F_{(6,180)}=16.62, p<0.0001 ; F_{(1,180)}=585.43, p<0.0001$; $F_{(6,180)}=3.07, p<0.0070$. Bonferroni post-hoc analysis showed that ACD group displayed an increase in the number of punished lever presses along the conflict period $(t=7.584, p<0.001$; $t=$ 5.583, $p<0.001 ; t=6.162, p<0.001 ; t=6.847, p<0.001 ; t=$ 8.980, $p<0.001 ; t=9.085, p<0.001 ; t=10.56, p<0.001)$ when compared to controls (Figure 4B), reaching an average amount of ACD ingested of $43 \pm 23 \mathrm{mg} / \mathrm{kg}$.

When animals received AM281, statistical analysis by a TwoWay ANOVA for repeated measures including AM281 treatment as the between-subjects factor and "Days" as withinsubjects factor, showed a significant effect of time, treatment, and their interaction on the number of unpunished responses emitted, $F_{(6,180)}=32.43, p<0.0001 ; F_{(1,180)}=38.50, p<0.0001$;
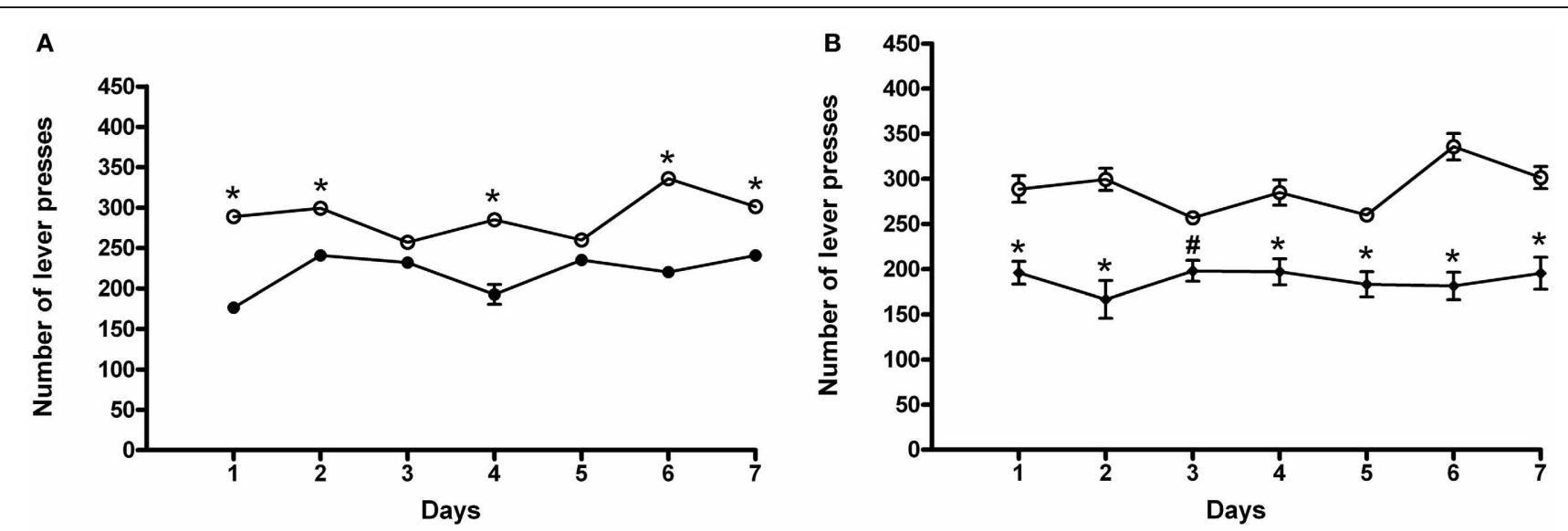

FIGURE 3 | Effects of ACD (A) and AM281 treatment (B) on the number of lever presses during the relapse periods. Each value represents the means \pm S.D. of 16 rats. ${ }^{\#} p<0.05 ;{ }^{*} p<0.001$ vs. respective controls. (๑) CTR, (O) ACD, (ACD-AM281). 
$F_{(6,180)}=5.09, p<0.0001$. Bonferroni post-hoc analysis showed that AM281 was able to induce a decrease in the number of unpunished lever presses in day $1,2,5(t=7.649, p<0.001$; $t=4.146, p<0.001 ; t=4.229, p<0.001)$ in ACD group compared to respective controls (Figure 5A), and lower amount of ACD consumed $(259 \pm 21 \mathrm{mg} / \mathrm{kg})$. When the parameter "punished responses" was analyzed after AM281 administration, the results of a Two-Way ANOVA for repeated measures, including ACD treatment as the between-subjects factor and "Days" as within-subjects factor, showed a significant effect of time, treatment, and their interaction on the number of responses emitted, $F_{(6,180)}=5.21, p<0.0001 ; F_{(1,180)}=328.73, p<0.0001$; $F_{(6,180)}=4.19, p<0.0001$. Bonferroni post-hoc analysis showed that AM281 was able to induce a decrease in the number of punished lever presses along the conflict period $(t=12.01, p<$ $0.001 ; t=7.791, p<0.001 ; t=6.779, p<0.001 ; t=6.203, p<$
$0.001 ; t=7.345, p<0.001 ; t=9.057, p<0.001 ; t=9.280, p<$ 0.001) (Figure 5B) compared to their respective controls, reaching an average amount of ACD ingested of $12 \pm 1 \mathrm{mg} / \mathrm{kg}$. No significant difference in the number of unpunished and punished responses was recorded when AM281 was administered to control rats.

\section{DISCUSSION}

The aim of the current study was to evaluate whether ACD could induce and maintain a self-administration drinking behavior in an operant-conditioning paradigm which consisted of training-, extinction-, reinstatement and conflict phases (Cannizzaro et al., 2011; Cacace et al., 2012), in order to demonstrate ACD reinforcing and motivational properties. Afterwards we pointed at exploring the effect of AM281, a CB1 antagonist, on drug-seeking, drug-taking and drug-induced compulsive-like behavior.
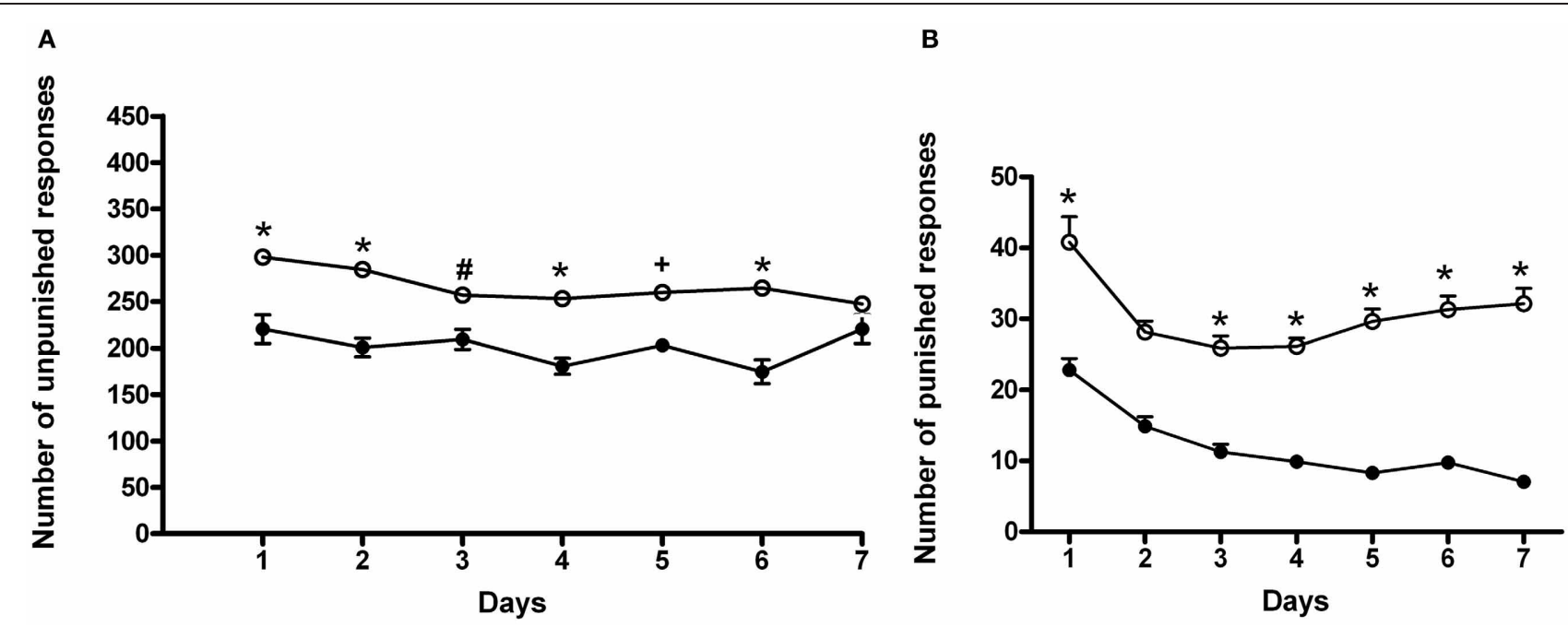

FIGURE 4 | Differences in the number of unpunished (A) and punished (B) responses during the conflict periods in ACD-and in water-drinking rats. Each value represents the means \pm S.D. of 16 rats. ${ }^{\#} p<0.05 ;{ }^{+} p<0.01 ;{ }^{*} p<0.001$ vs. control groups. (•) CTR, (O) ACD.
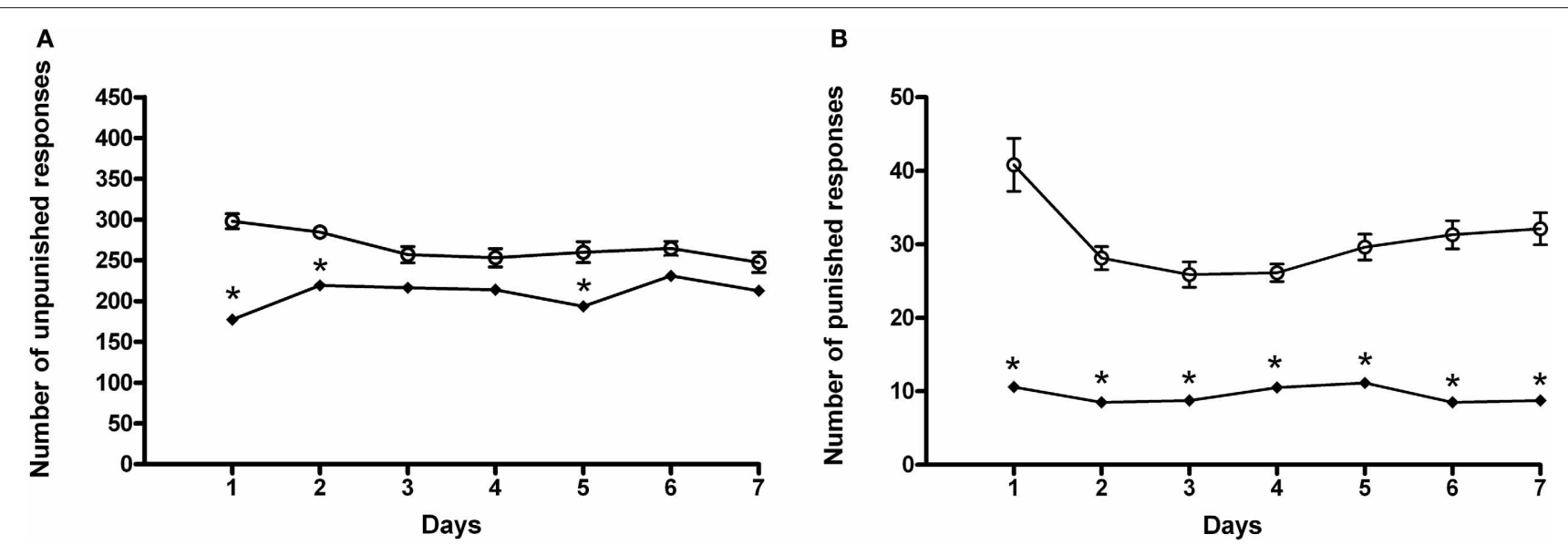

FIGURE 5 | Effects of the administration of AM281 on the number of unpunished (A) and punished (B) responses during the conflict periods in $A C D$ treated rats. Each value represents the means \pm S.D. of sixteen rats. ${ }^{*} p<0.001$ vs. control groups. (O) ACD, (ACD-AM281). 
There is increasing interest in developing animal models that more closely mimic addiction diagnostic criteria (DSM-IV-TR, American Psychiatric Association, 2000) than classical reinstatement models (Vanderschuren and Ahmed, 2012). Based on this awareness, the experimental protocol implemented in the present study aimed at evaluating the co-occurrence of various aspects of the addictive phenotype, such as the increase in drug use over time; difficulty in restricting drug intake or consuming more than intended; perseveration in drug abuse despite its negative consequences. Our data show that ACD exerted motivational and reinforcing activity, since it was able to induce and maintain an operant drinking behavior; it induced drug-seeking during extinction, and a relapse behavior after 1-week forced abstinence; remarkably, ACD rats displayed a higher emission of punished responses with respect to controls, in a modified Geller-Seifter conflict procedure, which may efficaciously model compulsive drug taking despite negative consequences.

In detail, our results confirm data from a previous study (Cacace et al., 2012), showing that rats readily acquire ACD operant self-administration, according to a fixed ratio of reinforcement, during the training sessions. The number of lever presses for ACD increased over the 3 weeks of training, significantly overcoming control group's lever presses for water from the second week. Moreover when animals were allowed to freely access to water, no significant differences in water intake were observed between the two groups, a finding that accounts for ACD specific motivational effects.

Given that escalation of drug intake is a well-known phenomenon in oral ethanol self-administration studies (Wise, 1973), our data clearly show that ACD shares this feature with ethanol and suggest a direct role in the progressive loss of control over drinking behavior. Difficulty in abstaining from drug use can be studied in animals by assessing drug seeking when the drug is no longer available that is to say extinction paradigm (Ahmed, 2012). Our results indicate that ACD induced a drugseeking behavior, since ACD group emitted a significantly higher number of lever presses in the extinction experiment with respect to controls. ACD-self administering rats persisted in responding in an attempt to earn the rewarding substance, due to the motivational property of ACD; in fact water self-administering rats showed an earlier extinction of responding, due to the lower value of the reward. This finding allows us to speculate that in ACD group the formation of specific ACD-related associations becomes overly salient, thus enhancing craving for ACD. In the operant conditioning paradigm, reinstatement refers to the rapid resumption of drug-reinforced operant response in animals previously extinguished from drug self-administration training (Marchant et al., 2013). This experimental model mirrors the relapse behavior observed in humans, the most troublesome facet of addiction. ACD oral self-administration sustained a reinstatement in animals. Indeed, ACD-rats, previously exposed to extinction and 1-week forced abstinence, displayed a higher number of lever presses with respect to controls, during the relapse phase. Furthermore, in the first relapse day, lever presses for ACD were higher than in the last training day, suggesting that ACD maintained acute reinforcing strength and motivation even after extinction and deprivation (Martin-Fardon and Weiss, 2013). It is well-known that repeated drug use leads enhances the salience attributed to drugs and drug-associated contexts (Robinson and Berridge, 2008), increasing their consumption following periods of abstinence (Hölter et al., 1998; Rodd et al., 2003). Accordingly, ACD-drinking rats showed a ready resumption of the operant drinking behavior, and displayed a significant effect of deprivation, suggesting that ACD might be also involved in alcohol deprivation effect during relapse (Spanagel and Hölter, 1999).

Drug self-administration in the presence of responsecontingent shock punishment highlights the motivational properties of substances and it reliably models compulsive drug use despite adverse consequences (Deroche-Gamonet et al., 2004). Moreover, increasing attention is paid to addiction models that focus on punishment-resistance, as a core feature in capturing the addictive phenotype (Vanderschuren and Ahmed, 2012). Given these premises, we developed the operant-conflict procedure in order to assess whether ACD consumption itself was resistant to aversive consequences associated to drug intake. In the operant-conflict procedure, responses were alternatively paired to a footshock, signaled by a light-cue. In the conflict paradigm rats suffer from the "conflict" between the drive to drink and the fear of the shock: this usually leads to a suppression of conditioned responses for reinforcement. The aversive stimulus has a general dissuasive effect in the operant behavior for water, as it strongly decreases the number of lever presses in CTR group. Despite its highly negative value, the contingent punishment less effectively inhibited operant responding for ACD, and a higher number of punished responses was observed, with respect to controls. It seemed that ACD shares ethanol anti-conflict properties (Baldwin et al., 1991), but since ACD-rats showed an increase both in punished and unpunished responses, it is reasonable to interpret our data recalling ACD strong motivational properties, rather than an anti-conflict effect. Indeed, ACD appears to be a 1000-fold more potent reinforcement than ethanol in the posterior VTA (Rodd et al., 2005). Besides, ACD involvement in recruiting the neuroendocrine stress system (Cannizzaro et al., 2010; Escrig et al., 2012) may be crucial in the development of negative emotional states, thus leading to the progressive loss of control in drinking behavior and compulsive alcohol intake (Koob, 2013). A major finding of the present study was the pharmacological probing of ACD reinforcing and motivational properties, addressing the AM281 effect in the distinct addiction-related behaviors explored, namely drug-seeking, relapse and punishment resistance. Recent preclinical and clinical data indicate that CB1 receptor antagonists, such as SR141716A (SR, Rimonabant), can reduce self-administration and craving for several commonly addictive drugs (Colombo et al., 1998; De Vries et al., 2001; Navarro et al., 2001; Cohen et al., 2005; Rigotti et al., 2009). CB1 function is required for ethanol-mediated activation of VTA DA neurons (Cheer et al., 2007), supporting the hypothesis that ethanol rewarding properties are due in part to ECs release, which likely exerts reduction of GABA inhibition onto VTA dopamine neurons (Lupica and Riegel, 2005; Barrot et al., 2012). This effect is quite specific, since the neuroanatomical loci of the SR-mediated reduction in ethanol self-administration involve brain regions typically associated with addiction; indeed SR microinjections into VTA, medial prefrontal cortex and NAcc reduce ethanol self-administration, 
whereas injections into the dorsal striatum do not affect the number of responses for ethanol (Caillé et al., 2007; Hansson et al., 2007; Malinen and Hyytiä, 2008). AM281 is structurally related to SR, but displays higher affinity and specificity for CB1 receptor (Gatley et al., 1998), since it does not interact with GPR55 and opioid receptors (Seely et al., 2012). Our results show that AM281 administration was able to decrease ACDseeking, ACD-relapse after forced abstinence, and ACD-induced resistance to punishment in highly predictive experimental procedures. Indeed, animals receiving the CB1 antagonist emitted a lower number of responses for ACD with respect to vehicle group during extinction. This evidence suggests that ACD positive incentive properties underlie perseveration in lever pressing when reinforce delivery is suspended. No significant effect was recorded in water-administering rats, ruling out an aspecific action on operant responding. AM281 administration induced a significant reduction in lever-pressing during the relapse session, when compared to their respective controls. This finding further suggests a role for CB1 receptor in ACD-induced as well as it has been reported in alcohol-related addictive behavior (Serrano and Parsons, 2011). Ultimately, AM281 administration in the conflict paradigm decreased the number of punished lever presses for ACD, and a similar though less evident effect was observed in unpunished ones. At this regard, an aspecific effect of the

\section{REFERENCES}

Ahmed, S. H. (2012). The science of making drug-addicted animals. Neuroscience 211, 107-125. doi: 10.1016/j.neuroscience.2011.08.014

American Psychiatric Association. (2000). Diagnostic and Statistical Manual of Mental Disorders, IV-TR $E d n$. Washington, DC: American Psychiatric Association.

Amit, Z., Brown, Z. W., and Rockman, G. E. (1977). Possible involvement of acetaldehyde, norepinephrine and their tetrahydroisoquinoline derivatives in the regulation of ethanol self-administration. Drug Alcohol Depend. 2, 495-500. doi: 10.1016/0376-8716(77)90049-7

Arizzi-LaFrance, M. N., Correa, M., Aragon, C. M. G., and Salamone, J. D. (2006). Motor stimulant effects of ethanol injected into the substantia nigra pars reticulata: importance of catalase-mediated metabolism and the role of acetaldehyde. Neuropsychopharmacology 31, 997-1008. doi: 10.1038/ sj.npp. 1300849

Arnone, M., Maruani, J., Chaperon, F., Thiébot, M. H., Poncelet, M., Soubrié, P., et al. (1997). Selective inhibition of sucrose and ethanol intake by SR 141716, an antagonist of central cannabinoid (CB1) receptors. Psychopharmacology 132, 104-106.

Baldwin, H. A., Wall, T. L., Schuckit, M. A., and Koob, G. F. (1991).
Differential effects of ethanol on punished responding in the $\mathrm{P}$ and NP rats. Alcohol. Clin. Exp. Res. 15, 700-704. doi: 10.1111/j.15300277.1991.tb00582.x

Barrot, M., Sesack, S. R., Georges, F., Pistis, M., Hong, S., and Jhou, T. C. (2012). Braking dopamine systems: a new GABA master structure for mesolimbic and nigrostriatal functions. J. Neurosci. 32, 14094-14101. doi: 10.1523/JNEUROSCI.3370-12.2012

Basavarajappa, B. S., Cooper, T. B., and Hungund, B. L. (1998). Chronic ethanol administration downregulates cannabinoid receptors in mouse brain synaptic plasma membrane. Brain Res. 793, 212-218. doi: 10.1016/S0006-8993(98)00175-9

Basavarajappa, B. S., Saito, M., Cooper, T. B., and Hungund, B. L. (2000). Stimulation of cannabinoid receptor agonist 2-arachidonylglycerol by chronic ethanol and its modulation by specific neuromodulators in cerebellar granule neurons. Biochim. Biophys. Acta 1535, 78-86. doi: $\quad 10.1016 / S 0925-4439(00)$ 00085-5

Basavarajappa, B. S., Saito, M., Cooper, T. B., and Hungund, B. L. (2003). Chronic ethanol inhibits the anandamide transport and increases extracellular anandamide levels in cerebellar granule neurons. Eur. J. Pharmacol. 466, 73-83. doi: 10.1016/S0014-2999(03)01557-7

CB1 antagonist on motor activity seems unlikely, since AM281 administration was able to affect unpunished responses for ACD discontinuously, while the reduction of punished responses occurred along the whole conflict period. This effect may be related to a decrease in the incentive for lever-pressing due to the pharmacological treatment. The clear influence of CB1 receptor activity on ACD-induced punishment resistance further highlights the involvement of the reward-processing machinery as the intrinsic mechanisms underlying ACD-related behavioral features. As a matter of fact, these data provide evidence of ACD incentive properties, whose contribution must be taken into account in studying and treating ethanol-related behaviors. The neural substrates underpinning rewarding properties of orally self-administer ACD involve CB1 receptors, which are able to indirectly modulate DA mesocorticolimbic pathway. Drugs able to manipulate EC system might represent a useful therapeutic strategy affecting both ethanol and its neuroactive metabolite actions on crucial addiction-related behaviors, such as drug seeking, relapse and drug abuse despite negative consequences. This study aims at representing a step forward in elucidating the complex framework of actors playing a role in maintaining ethanol addiction; nevertheless further efforts are needed to fully characterize the actual contribution of ACD to ethanol's effects.

Brown, Z. W., Amit, Z., and Rockman, G. E. (1979). Intraventricular selfadministration of acetaldehyde, but not ethanol, in naive laboratory rats. Psychopharmacology (Berl.) 64, 271-276. doi: 10.1007/BF00427509

Cacace, S., Plescia, F., Barberi, I., and Cannizzaro, C. (2012). Acetaldehyde oral selfadministration: evidence from the operant-conflict paradigm. Alcohol. Clin. Exp. Res. 36, 1278-1287. doi: 10.1111/j.1530-0277.2011.01725.x

Caillé, S., Alvarez-Jaimes, L., Polis, I., Stouffer, D. G., and Parsons, L. H. (2007). Specific alterations of extracellular endocannabinoid levels in the nucleus accumbens by ethanol, heroin, and cocaine self-administration. J. Neurosci. 27, 3695-3702. doi: 10.1523/JNEUROSCI.4403-06.2007

Cannizzaro, C., La Barbera, M., Plescia, F., Cacace, S., and Tringali, G. (2010). Ethanol modulates corticotropin releasing hormone release from the rat hypothalamus: does acetaldehyde play a role? Alcohol. Clin. Exp. Res. 34, 588-593. doi: 10.1111/j.1530-0277.2009.01127.x

Cannizzaro, C., Plescia, F., and Cacace, S. (2011). Role of acetaldehyde in alcohol addiction: current evidence and future perspectives. Malta Med. J. 23, 27.

Cheer, J. F., Wassum, K. M., Sombers, L. A, Heien, M. L., Ariansen, J. L., Aragona, B. J., et al. (2007).
Phasic dopamine release evoked by abused substances requires cannabinoid receptor activation. J. Neurosci. 27, 791-795. doi: 10.1523/JNEUROSCI.4152-06.2007 Cippitelli, A., Bilbao, A., Hansson, A. C., Del Arco, I., Sommer, W., Heilig, M., et al. (2005). Cannabinoid $\mathrm{CB} 1$ receptor antagonism reduces conditioned reinstatement of ethanol-seeking behavior in rats. Eur. J. Neurosci. 21, 2243-2251. doi: 10.1111/j.1460-9568.2005.04056.x

Cohen, C., Kodas, E., and Griebel, G. (2005). CB1 receptor antagonists for the treatment of nicotine addiction. Pharmacol. Biochem. Behav. 81, 387-395. doi: 10.1016/j.pbb.2005.01.024

Colombo, G., Agabio, R., Fà, M., Guano, L., Lobina, C., Loche, A., et al. (1998). Reduction of voluntary ethanol intake in ethanol-preferring sP rats by the cannabinoid antagonist SR-141716. Alcohol Alcohol. 33, 126-130.

Correa, M., Salamone, J. D., Segovia, K. N., Pardo, M., Longoni, R., Spina, L., et al. (2012). Piecing together the puzzle of acetaldehyde as a neuroactive agent. Neurosci. Biobehav. Rev. 36, 404-430. doi: 10.1016/j.neubiorev.2011.07.009

De Bruin, N. M. W. J., Lange, J. H., Kruse, C. G., Herremans, A. H., Schoffelmeer, A. N., Van Drimmelen, M., et al. (2011). SLV330, a cannabinoid $\mathrm{CB}(1)$ 
receptor antagonist, attenuates ethanol and nicotine seeking and improves inhibitory response control in rats. Behav. Brain Res. 217, 408-415. doi: 10.1016/j.bbr.2010.11.013

Deehan, G. A., Brodie, M. S., and Rodd, Z. A. (2013a). What is in that drink: the biological actions of ethanol, acetaldehyde, and salsolinol. Curr. Top. Behav. Neurosci. 13, 163-184. doi: 10.1007/7854_2011_198

Deehan, G. A. Jr., Engleman, E. A., Ding, Z. M., McBride W. J., and Rodd. Z. A. (2013b). Microinjections of acetaldehyde or salsolinol into the posterior ventral tegmental area increase dopamine release in the nucleus accumbens shell. Alcohol. Clin. Exp. Res. 37, 722-729. doi: 10.1111/acer.12034.

Deroche-Gamonet, V., Belin, D., and Piazza, P. V. (2004). Evidence for addiction-like behavior in the rat. Science 305, 1014-1017.

De Vries, T. J., Shaham, Y., Homberg, J. R., Crombag, H., Schuurman, K., Dieben, J., et al. (2001). A cannabinoid mechanism in relapse to cocaine seeking. Nat. Med. 7, 1151-1154. doi: 10.1038/nm10011151

Economidou, D., Mattioli, L., Cifani, C., Perfumi, M., Massi, M., Cuomo, V., et al. (2006). Effect of the cannabinoid CB1 receptor antagonist SR-141716A on ethanol self-administration and ethanol-seeking behaviour in rats. Psychopharmacology 183, 394-403. doi: 10.1007/s00213-0050199-9

Escrig, M. A., Pardo, M., Aragon, C. M., and Correa, M. (2012). Anxiogenic and stress-inducing effects of peripherally administered acetaldehyde in mice: similarities with the disulfiramethanol reaction. Pharmacol. Biochem. Behav. 100, 404-412. doi: 10.1016/j.pbb.2011.10.002

Femenía, T., García-Gutiérrez, M. S., and Manzanares, J. (2010). CB1 receptor blockade decreases ethanol intake and associated neurochemical changes in fawn-hooded rats. Alcohol. Clin. Exp. Res. 34, 131-141. doi: 10.1111/j.1530-0277.2009.01074.x

Gallate, J. E., and McGregor, I. S. (1999). The motivation for beer in rats: effects of ritanserin, naloxone and SR 141716. Psychopharmacology 142, 302-308. doi: 10.1007/s002130050893

Gatley, S. J., Lan, R., Volkow, N. D., Pappas, N., King, P., Wong, C. T., et al. (1998). Imaging the brain marijuana receptor: development of a radioligand that binds to cannabinoid CB1 receptors in vivo. J. Neurochem. 70, 417-423. doi: 10.1046/j.14714159.1998.70010417.x

Getachew, B., Hauser, S. R., Dhaher, R., Katner, S. N., Bell, R. L., Oster, S. M., et al. (2011). CB1 receptors regulate alcoholseeking behavior and alcohol self-administration of alcoholpreferring (P) rats. Pharmacol. Biochem. Behav. 97, 669-675. doi: 10.1016/j.pbb.2010.11.006

Hansson, A. C., Bermúdez-Silva, F. J., Malinen, H., Hyytiä, P., SanchezVera, I., Rimondini, R., et al. (2007). Genetic impairment of frontocortical endocannabinoid degradation and high alcohol preference. Neuropsychopharmacology 32, 117-126. doi: 10.1038/sj.npp. 1301034

Hölter, S. M., Engelmann, M., Kirschke, C., Liebsch, G., Landgraf, R., and Spanagel, R. (1998). Longterm ethanol self-administration with repeated ethanol deprivation episodes changes ethanol drinking pattern and increases anxiety-related behaviour during ethanol deprivation in rats. Behav. Pharmacol. 9, 41-48.

Jamal, M., Ameno, K., Uekita, I., Kumihashi, M., Wang, W., and Ijiri, I. (2007). Catalase mediates acetaldehyde formation in the striatum of free-moving rats. Neurotoxicology 28, 1245-1248. doi: 10.1016/j.neuro.2007.05.002

Karahanian, E., Quintanilla, M. E., Tampier, L., Rivera-Meza, M. Bustamante, D., Gonzalez-Lira, V., et al. (2011). Ethanol as a prodrug: brain metabolism of ethanol mediates its reinforcing effects. Alcohol. Clin. Exp. Res. 35, 606-612. doi: 10.1111/j.1530-0277.2011.01439.x

Koob, G. F. (2013). Theoretical frameworks and mechanistic aspects of alcohol addiction: alcohol addiction as a reward deficit disorder. Curr. Top. Behav. Neurosci. 13, 3-30. doi: 10.1007/7854_2011_129

Lupica, C. R., and Riegel, A. C. (2005). Endocannabinoid release from midbrain dopamine neurons: a potential substrate for cannabinoid receptor antagonist treatment of addiction. Neuropharmacology 48, 1105-1116. doi: 10.1016/ j.neuropharm.2005.03.016

Malinen, H., and Hyytiä, P. (2008). Ethanol self-administration is regulated by $\mathrm{CB} 1$ receptors in the nucleus accumbens and ventral tegmental area in alcoholpreferring AA rats. Alcohol. Clin.
Exp. Res. 32, 1976-1983. doi: 10.1111/j.1530-0277.2008.00786.x

Marchant, N. J., Li, X., and Shaham, Y. (2013). Recent developments in animal models of drug relapse. Curr. Opin. Neurobiol. doi: 10.1016/j.conb.2013.01.003

Martin-Fardon, R., and Weiss, F. (2013). Modeling relapse in animals. Curr. Top. Behav. Neurosci. 13, 403-432. doi 10.1007/7854_2012_202

Melis, M., Enrico, P., Peana, A. T., and Diana, M. (2007). Acetaldehyde mediates alcohol activation of the mesolimbic dopamine system. Eur. J. Neurosci. 26, 2824-2833. doi: $\quad 10.1111 /$ j.1460-9568.2007. 05887. $x$

Melis, M., Muntoni, A. L., and Pistis, M. (2012). Endocannabinoids and the processing of value-related signals. Front. Pharmacol. 3:7. doi 10.3389/fphar.2012.00007

Myers, W. D., Ng, K. T., and Singer, G. (1982). Intravenous self-administration of acetaldehyde in the rat as a function of schedule, food deprivation and photoperiod. Pharmacol. Biochem. Behav. 17, 807-811. doi: 10.1016/0091-3057(82)90364-1

Navarro, M., Carrera, M. R., Fratta, W., Valverde, O., Cossu, G., Fattore, L., et al. (2001). Functional interaction between opioid and cannabinoid receptors in drug self-administration. J. Neurosci. 21, 5344-5350.

Peana, A. T., Enrico, P., Assaretti, A. R., Pulighe, E., Muggironi, G., Nieddu, M., et al. (2008). Key role of ethanol-derived acetaldehyde in the motivational properties induced by intragastric ethanol: a conditioned place preference study in the rat. Alcohol. Clin. Exp. Res. 32, 249-258. doi: 10.1111/j.15300277.2007.00574.x

Peana, A. T., Muggironi, G., and Diana, M. (2010). Acetaldehydereinforcing effects: a study on oral self-administration behavior. Front. Psychiatry 1:23. doi: 10.3389/fpsyt.2010.00023

Quertemont, E., Tambour, S., and Tirelli, E. (2005). The role of acetaldehyde in the neurobehavioral effects of ethanol: a comprehensive review of animal studies. Prog. Neurobiol. 75, 247-274. doi 10.1016/j.pneurobio.2005.03.003

Rigotti, N. A., Gonzales, D., Dale, L. C., Lawrence, D., and Chang, Y. (2009). A randomized controlled trial of adding the nicotine patch to rimonabant for smoking cessation: efficacy, safety and weight gain. Addiction 104
266-276. doi: 10.1111/j.13600443.2008.02454.x

Robinson, T. E., and Berridge, K. C. (2008). Review. The incentive sensitization theory of addiction: some current issues. Philos. Trans. R. Soc. Lond. B Biol. Sci. 363, 3137-3146. doi: 10.1098/rstb.2008.0093

Rodd, Z. A., Bell, R. L., Kuc, K. A., Murphy, J. M., Lumeng, L., Li, T. K., et al. (2003). Effects of repeated alcohol deprivations on operant ethanol self-administration by alcohol-preferring (P) rats. Neuropsychopharmacology 28, 1614-1621. doi: 10.1038/sj.npp. 1300214

Rodd, Z. A., Bell, R. L., Zhang, Y., Murphy, J. M., Goldstein, A., Zaffaroni, A., et al. (2005). Regional heterogeneity for the intracranial self-administration of ethanol and acetaldehyde within the ventral tegmental area of alcohol-preferring (P) rats: involvement of dopamine and serotonin. Neuropsychopharmacology 30, 330-338. doi: 10.1038/ sj.npp. 1300561

Seely, K. A., Brents, L. K., Franks, L. N., Rajasekaran, M., Zimmerman, S. M., Fantegrossi, W. E., et al. (2012). AM-251 and rimonabant act as direct antagonists at muopioid receptors: implications for opioid/cannabinoid interaction studies. Neuropharmacology 63, 905-915. doi: 10.1016/ j.neuropharm.2012.06.046

Serrano, A., and Parsons, L. H. (2011). Endocannabinoid influence in drug reinforcement, dependence and addiction-related behaviors. Pharmacol. Ther. 132, 215-241. doi: 10.1016 j.pharmthera.2011.06.005

Smith, B. R., Amit, Z., and Splawinsky, J. (1984). Conditioned place preference induced by intraventricular infusions of acetaldehyde. Alcohol 1, 193-195. doi: 10.1016/0741-8329(84)90097-1

Spanagel, R., and Hölter, S. M. (1999). Long-term alcohol selfadministration with repeated alcohol deprivation phases: an animal model of alcoholism? Alcohol Alcohol. 34, 231-243. doi: 10.1093/alcalc/34.2.231

Vanderschuren, L. J. M. J., and Ahmed, S. H. (2012). Animal studies of addictive behavior. Cold Spring Harb. Perspect. Med. doi: 10.1101/cshperspect.a011932

Vinod, K. Y., Yalamanchili, R., Xie, S., Cooper, T. B., and Hungund, B. L. (2006). Effect of chronic ethanol exposure and its withdrawal on the endocannabinoid 
system. Neurochem. Int. 49, 619-625. doi: 10.1016/j.neuint. 2006.05.002

Wise, R. A. (1973). Voluntary ethanol intake in rats following exposure to ethanol on various schedules. Psychopharmacologia 29, 203-210. doi: 10.1007/BF00414034

Zakhari, S. (2006). Overview: how is alcohol metabolized by the body? Alcohol Res. Health 29, 245-254.
Zimatkin, S. M., Liopo, A. V., and Deitrich, R. A. (1998). Distribution and kinetics of ethanol metabolism in rat brain. Alcohol. Clin. Exp. Res. 22, 1623-1627. doi: 10.1111/j.15300277.1998.tb03958.x

Conflict of Interest Statement: The authors declare that the research was conducted in the absence of any commercial or financial relationships that could be construed as a potential conflict of interest.

Received: 20 March 2013; accepted: 22 May 2013; published online: 11 June 2013.

Citation: Plescia F, Brancato A, Marino RAM and Cannizzaro C (2013) Acetaldehyde as a drug of abuse: insight into AM281 administration on operantconflict paradigm in rats. Front. Behav.
Neurosci. 7:64. doi: 10.3389/fnbeh. 2013.00064

Copyright (c) 2013 Plescia, Brancato, Marino and Cannizzaro. This is an open-access article distributed under the terms of the Creative Commons Attribution License, which permits use, distribution and reproduction in other forums, provided the original authors and source are credited and subject to any copyright notices concerning any thirdparty graphics etc. 